\title{
The Antigens of Pseudomonas aeruginosa Studied by the Ouchterlony Technique and Immuno-electrophoresis
}

\author{
By D. VAN EEDEN* \\ Department of Bacteriology and Virus Research Unit, \\ University of Cape Town, Cape Town, South Africa
}

(Accepted for publication 17 February 1967)

\begin{abstract}
SUMMARY
Preliminary agglutination and precipitin tests to which 60 newly isolated strains of Pseudomonas aeruginosa were submitted confirmed the existence of at least five serological groups. Ouchterlony precipitin tests and immunoelectrophoresis experiments, made with the concentrated trichloroacetic acid extracts of eight strains representative of these groups, revealed the antigenic heterogeneity of this species while the presence of at least 12 antigens was demonstrated. One of these was common to seven of the eight strains. Each of five strains, representative of five different serological groups, possessed at least one antigen peculiar to itself. The remaining ones appeared to be distributed at random among the strains. At least three different antigens migrated towards the positive electrode, of which two appeared to be electrophoretically inhomogeneous.
\end{abstract}

\section{INTRODUCTION}

Various attempts have been made to differentiate between members of Pseudomonas aeruginosa by determining intraspecific variations (Seleen \& Stark, 1943; Holloway, 1960; and others). Grouping of strains of this species on the basis of antigenic structure has also attracted much attention (Aoki, 1926; Sandiford, 1937; Gaby, 1946; Mayr-Harting, 1948; Christie, 1948; Munoz, Scherago \& Weaver, 1949; Homma, Sagehashi \& Hosoya, 1951; Verder \& Watt, 1953; Gould \& McLeod, 1960) and might be expected to provide a means for detecting minor differences between strains. Agglutination tests, however, have given rather disappointing results, partly because of difficulties in distinguishing flagellar from somatic antigens (see for example MayrHarting (1948) and some experiments briefly reported in the present paper). Precipitin tests made with bacterial extracts (van den Ende, 1952; Köhler, 1957), though useful and more precise, cannot be regarded as providing a perfect criterion for comparison of strains because they fail to reveal the number of antigens forming the precipitate of which the nature can only be elucidated by comprehensive absorption experiments.

The present paper describes the application of the gel precipitin test (Ouchterlony, $1949,1953)$ to this problem. As the interpretation of Ouchterlony experiments is not always straightforward, confirmation of the results was sought by immuno-electrophoresis (Grabar \& Williams, 1955; Cleve \& Schwick, 1957; Hirschfeld, 1959, 1960; Lapresle, Kaminsky \& Tanner, 1959). Though used to examine only a few strains of

\footnotetext{
* Present address: Department of Microbiology, Potchefstroom University, Potchefstroom, South Africa.
} 
Pseudomonas aeruginosa, the methods gave results which seem to explain some of the difficulties previously encountered in the serological classification of this organism and provide some additional information about the antigens.

\section{METHODS}

Collection and preservation of strains. Sixty strains of Pseudomonas aeruginosa (labelled E1 to E60) were isolated from specimens, all of human origin, submitted to the Department of Pathology for bacteriological examination.

A pure culture of each strain was maintained on Hartley's digest agar (HA) slopes. In addition, each strain was preserved in the dry state (Stamp, 1947). Since Pseudomonas aeruginosa is a proteolytic organism, the desiccator was kept in a refrigerator until the nutrient gelatin had dried to thin pellets. A fresh subculture was prepared for each experiment by inoculating a dried pellet into Difco Nutrient Broth (DNB).

Preliminary agglutination and precipitin tests. In the first series of experiments all the strains were tested against immune sera prepared by van den Ende (1952) which had been stored at $-20^{\circ}$. Bacterial suspensions for flagellar $(\mathrm{H})$ and somatic $(\mathrm{O})$ agglutination, and trichloroacetic acid (TCA) extracts for precipitin tests were prepared, and the experiments were made as described by van den Ende (1952).

For precipitin tests the extracts were diluted $1 / 2$ in $0.87 \%(\mathrm{w} / \mathrm{v}) \mathrm{NaCl}$ solution and the antisera $1 / 10$ in $0.87 \%(\mathrm{w} / \mathrm{v}) \mathrm{NaCl}$ containing $5 \%(\mathrm{w} / \mathrm{v})$ sucrose. Every $5 \mathrm{~min}$, for $2 \mathrm{hr}$, the tubes were examined for rings of precipitate at the interface and, after being left overnight at room temperature, for precipitates which had settled.

In the second series of experiments cross-agglutination tests, both $\mathrm{H}$ and $\mathrm{O}$, were made with $\mathrm{H}$ and $\mathrm{O}$ suspensions of the homologous strains and the new antisera (see next section). Antiserum dilutions of $1 / 100$ were used. The newly prepared $H$ antisera and TCA extracts of the homologous strains were used in cross-precipitin tests. Antiserum dilutions of $1 / 10$ were used against $1 / 2$ dilutions of the extracts.

Preparation of immune sera. $\mathrm{H}$ and $\mathrm{O}$ immune sera were prepared from 14 strains, thought on the basis of preliminary tests to include at least one representative of the groups of van den Ende (1952). H antisera were prepared against formalinized whole organisms and $\mathrm{O}$ antisera against organisms which had been heated and treated with ethanol as described by van den Ende (1952), one rabbit being used for each suspension. The sera were sterilized by filtration, preserved with thiomersalate $(0.01 \%, \mathrm{w} / \mathrm{v})$ and tested by agglutination of homologous $\mathrm{H}$ and $\mathrm{O}$ bacterial suspensions.

Preparation of TCA extracts. Preliminary experiments showed that the antigen concentration in extracts prepared as described by van den Ende (1952) was inadequate for gel precipitin tests. Larger quantities of culture were therefore used for these experiments and the antigen extracts were concentrated before being tested. The selected strains were grown in oxygenated H.I.D. medium (Mead \& van den Ende, 1953), at $37^{\circ}$ for $15 \mathrm{hr}$ in $700 \mathrm{ml}$. volumes in 11 . bottles; tributyl phosphate was used as antifoam. The bacteria were collected by centrifugation at $5000 \mathrm{rev} . / \mathrm{min}$. for $30 \mathrm{~min}$. in a refrigerated angle-head centrifuge, washed twice in ice-cold distilled water and resuspended in $10 \mathrm{ml}$. ice-cold $0.25 \mathrm{~N}$-trichloroacetic acid/g. wet wt bacteria (Boivin \& Mesrobeanu, 1933). The mixture was stirred at $0-4^{\circ}$ for $3 \mathrm{hr}$ and then centrifuged in a refrigerated centrifuge at $3000 \mathrm{rev} . / \mathrm{min}$. for $30 \mathrm{~min}$. or until the supernatant fluid was 
clear; this was then treated with 0.5 vol. pre-cooled $0.5 \mathrm{M}-\mathrm{Na}_{2} \mathrm{HPO}_{4}$ and adjusted to pH 7.2 with $0.25 \mathrm{~N}-\mathrm{NaOH}$.

The extracts were dialysed for 2 days against four changes of distilled water containing $0.01 \%(\mathrm{w} / \mathrm{v})$ thiomersalate, concentrated by pervaporation to about $5 \mathrm{ml}$. and freeze-dried. For Ouchterlony experiments the dried extract from $2 \mathrm{~g}$. wet bacteria was redissolved in $\mathbf{0 . 2} \mathrm{ml}$. complement fixation titration (c.f.t.) saline (Mayer, Osler, Bier \& Heidelberger, 1946).

Preparation of a concentrated multivalent antiserum and concentration of individual antisera. To aid detection by gel precipitin tests of as many antigens as possible, a mixture was prepared of $1 \mathrm{ml}$. of each of six $\mathrm{H}$ antisera, each representative of one of the serological groups of van den Ende (1952). The antisera selected were those against the strains: E52 (group I), E8 (group II), E55 (group III), E5 (group IV), E 1 (Group V), E58 (group VI). The globulin fraction was precipitated from the mixed sera by adding 0.5 vol. saturated $\left(\mathrm{NH}_{4}\right)_{2} \mathrm{SO}_{4}$, the mixture being left at room temperature for $3 \mathrm{hr}$. The precipitate was collected by centrifugation at $6000 \mathrm{rev} . / \mathrm{min}$. for $30 \mathrm{~min}$. and redissolved in $1.0 \mathrm{ml}$. distilled water. The solution was dialysed in a refrigerator against $500 \mathrm{ml} .0 .87 \%(\mathrm{w} / \mathrm{v}) \mathrm{NaCl}$ containing $0.01 \%(\mathrm{w} / \mathrm{v})$ thiomersalate for 3 days, the saline being changed at the onset of the second and third days. Finally, the solution (vol. $4.5 \mathrm{ml}$.) was dialysed for 1 day against saline, diluted $1 / 10$, and freeze-dried. The residue was redissolved in $0.5 \mathrm{ml}$. distilled water containing $0.01 \%(\mathrm{w} / \mathrm{v})$ thiomersalate as preservative. Each of the six antiserum samples was therefore twice concentrated. Each of the six individual antisera was also concentrated twice by freeze-drying and redissolving in half the original volume of water containing $0.01 \%(\mathrm{w} / \mathrm{v})$ thiomersalate.

Micro-Ouchterlony experiments. These were carried out in a gel of $1 \%(\mathrm{w} / \mathrm{v})$ washed agar (Dulbecco \& Vogt, 1954) in $0.87 \%(\mathrm{w} / \mathrm{v}) \mathrm{NaCl}$ on $9 \times 9 \mathrm{~cm}$. glass plates. The plates, laid on a level surface, were completely covered with a $1 \%(w / v)$ solution of washed agar in distilled water which was allowed to dry to a thin film at $37^{\circ}$ overnight. The surface of each plate was then sprinkled with a few granules of thiomersalate powder and carefully covered with $17.0 \mathrm{ml}$. of a hot solution of $1 \%$ washed agar in $0.87 \%(\mathrm{w} / \mathrm{v}) \mathrm{NaCl}$ to give a layer $2 \mathrm{~mm}$. thick. Holes of $2 \mathrm{~mm}$. diameter were cut in the agar with a small cutter. Sets of six holes were arranged hexagonally with a seventh in the centre. The distance between the centres of each pair of holes was $5 \mathrm{~mm}$. The holes on the outside were filled with solutions of the antigens under test and the centre one with concentrated immune serum. The plates were kept in a moist chamber and examined every day with a magnifying lens, for lines of precipitate which were recorded on a drawing.

After complete development of the lines, the plates were washed with $0.87 \%(w / v)$ $\mathrm{NaCl}$ containing $0.01 \%(\mathrm{w} / \mathrm{v})$ thiomersalate for 2 days and stained for $24 \mathrm{hr}$ with $0.002 \%(\mathrm{w} / \mathrm{v})$ nigrosine in $2 \%(\mathrm{v} / \mathrm{v})$ acetic acid in water. Finally, the plates were washed in $2 \%$ acetic acid for $6 \mathrm{hr}$ and the lines again recorded by drawing as well as photographing.

Immuno-electrophoresis. The method used was based on that of Grabar \& Williams (1955). A thin glass plate, $7.7 \mathrm{~cm} . \times 25.5 \mathrm{~cm}$., was covered with hot $1 \%(\mathrm{w} / \mathrm{v})$ aqueous agar (washed agar) which was allowed to dry at $37^{\circ}$ overnight. The plate was then covered with enough hot $1.5 \%(\mathrm{w} / \mathrm{v})$ solution of washed agar in sodium diethylbarbiturate $\mathrm{HCl}$ buffer (pH 8.2, ionic strength 0.05; Grabar \& Williams, 1955) to give a layer about $1 \mathrm{~mm}$. thick. When the gel had set, five holes, $1 \mathrm{~mm}$. in diameter and 
$11 \mathrm{~mm}$. apart, were punched in the agar in a straight transverse line near the centre of the plate. Each hole was filled with the concentrated TCA extract of one Pseudomonas aeruginosa strain prepared as previously described. The plate was placed on the watercooled floor of an enclosed Perspex apparatus resembling that of Paigen (1956). The ends of the agar were connected by several thicknesses of filter paper to large electrode vessels containing sodium diethylbarbiturate $\mathrm{HCl}$ buffer $(\mathrm{pH} 8 \cdot 2$, ionic strength $0 \cdot 1$ ) to which thiomersalate, $0.01 \%(\mathrm{w} / \mathrm{v})$, had been added. With cooling water at $5-10^{\circ}$ flowing through the floor of the covered apparatus, a direct current of $14 \mathrm{~mA}$., giving a gradient of $7.5 \mathrm{~V} / \mathrm{cm}$. in the gel, was applied for $1.5 \mathrm{hr}$. The plate was then removed and four grooves, $1 \mathrm{~mm}$. wide, were cut in the agar parallel to the long axis between and equidistant from each pair of holes. Each groove was filled with a different twice-concentrated $\mathbf{H}$ antiserum. The plate was kept in a moist chamber and examined daily for lines of precipitate, which were recorded. After a week the plate was washed and stained and the lines recorded, the procedure in each case being the same as that described for Ouchterlony experiments.

\section{RESULTS}

\section{Agglutination and precipitin tests}

In the first series with the sera of van den Ende (1952) many cross-reactions were observed, though in most cases these involved only trace reactions. From the results as a whole, 37 of 60 strains were shown to fall into one or another of the six van den Ende serological groups; for the rest a definite grouping was impossible.

In the cross-agglutination and precipitin experiments with the 14 newly prepared antisera, only the homologous strains were used. Because of many cross-reactions a clear-cut delimitation into groups was impossible in the case of $\mathrm{H}$ agglutination. The results of $\mathrm{O}$ agglutination suggested a definite grouping into at least five of the serological groups. Notwithstanding more abundant cross-reactions, in most cases only traces, the results of the precipitin reactions agreed well with those of $O$ agglutination.

\section{Ouchterlony precipitin experiments}

For these experiments eight strains, thought to be representative of five serological groups, were selected and concentrated TCA extracts were prepared. These strains were: E52 (group I), E 55 (group III), E5, E16 and E56 (group IV), E 1 (group V), E36 and E58 (group VI).

It was frequently observed that lines which were single when first formed split to form double lines within periods varying between $7 \mathrm{hr}$ and 3 days after the plates had been put up. Furthermore, on keeping the plates for several days, some of the lines which were definitely seen after 1 or 2 days either disappeared or were in the process of fading.

\section{Precipitin tests with multivalent antiserum}

In the first experiment (Fig. 1) the TCA extracts of strains E 1 and $\mathrm{E} 5$ were allowed to react with the multivalent antiserum (MS). In the first plate every alternate well was filled with extract of $\mathrm{E} 1$, the first with concentrated, the third with a $1 / 2$ and the fifth with a 1/4 dilution of the extract. On the second plate the same procedure was followed with the extract of $E 5$, while on the third plate the extracts of both strains were put up. 
With the extracts of $\mathrm{E} 1$ and $\mathrm{E} 5$ on separate plates the former formed a maximum of five and the latter three lines. On the third plate the extract of $\mathrm{E} 1$ produced four lines and that of E 5 produced two. One of the latter two lines appeared to join up with one line of $\mathrm{E} 1$ while the second line crossed all the lines of $\mathrm{E} 1$. These results suggest the presence of at least five antigens in $\mathrm{E} 1$ and three in $\mathrm{E} 5$ of which one is common.

In performing experiments with the eight selected strains, the design was such that each extract was in turn next to each of the other extracts. The extracts of all the strains, with the exception of $\mathrm{E} 58$, each produced a line near the antigen well which eventually

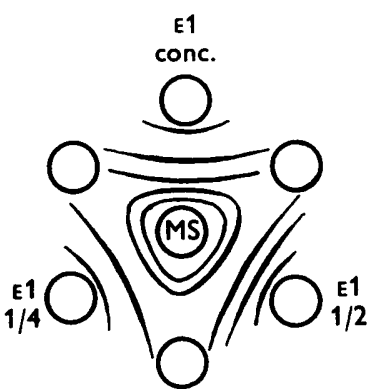

A

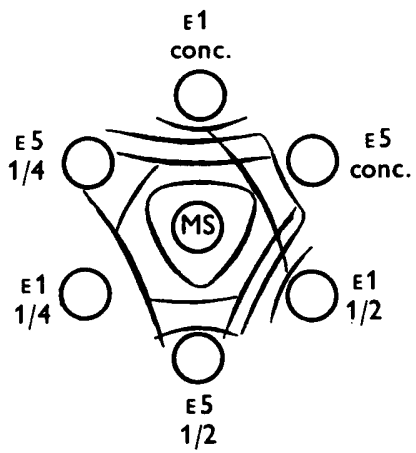

B

Fig. 1. Results of Ouchterlony precipitin tests with concentrated (conc.) and serial two-fold dilutions (1/2 and 1/4) of the trichloroacetic acid-extracts of Pseudomonas aeruginosa strains E 1 and E 5 against the concentrated multivalent antiserum (MS). A, Plate with concentrated and diluted extracts of $\mathrm{E} 1$ only. $\mathrm{B}$, Concentrated and diluted extracts of both strains on the same plate.

split up into two. For each extract these lines joined up with those of every other extract except for strain E 5 where identity with the lines of strains E 36, E 52 and E 55 was uncertain. For the latter three strains, however, like that of $\mathrm{E} 5$, the lines joined up with the corresponding lines of all the other strains. Furthermore, against the anti-E 1 serum (see next section) all the extracts, except that of E58, produced two similar lines which clearly joined up with one another.

In addition to the above-mentioned line the extracts of the various strains produced lines as follows:

$T C A$ extracts of $E 1$ and $E 36$. Each produced one line which joined up with one another.

$T C A$ extracts of $E 5$ and $E 16$. One exclusive line was produced by each.

$T C A$ extract of $E 52$. Two additional exclusive lines were produced.

$T C A$ extract of $E 58$. Altogether three exclusive lines were produced.

The results of these tests are summarized in Table 1.

\section{Precipitin tests with concentrated individual antisera}

The eight extracts described above were also used in Ouchterlony tests against each of the six individual $\mathrm{H}$ antisera, which had been included in the multivalent antiserum.

Against its homologous antiserum, the extract of $\mathrm{E} 1$ produced three lines. These appear to be different from those which were observed against the multivalent antiserum; their separation was incomplete and they presumably obscured the double 
line which, apparently, is common to all the strains except $\mathrm{E} 58$. Against this antiserum the extracts of the other strains, with the exception of E 58, each produced a double line near the antigen well and in each case it clearly joined up with those of every other extract. The following additional lines were produced against anti-E 1 serum by the various strains: one line by and common to $\mathrm{E} 5$ and $\mathrm{E} 16$ but not identical to any of the lines formed by $\mathrm{E} 1$; one by and common to $\mathrm{E} 52$ and $\mathrm{E} 1$; a double line by $\mathrm{E} 36$. Apparently it was the latter line which appeared as a single line against the multivalent antiserum. No lines were produced by the extract of E 58 . All the antigens which were demonstrated against this antiserum must be present in $\mathrm{E} 1$ otherwise the antiserum could not have showed them up.

The results produced against the remaining five antisera, as well as those described above, are summarized in Table 2.

Table 1. Summary of results of Ouchterlony experiments in which the TCA extracts of Pseudomonas aeruginosa strains were tested against the multivalent antiserum

Grouping of strains was based on precipitin tests with the antisera of van den Ende (1952)

\begin{tabular}{|c|c|c|c|c|c|c|}
\hline Strain & Group & $\begin{array}{l}\text { Total no. } \\
\text { of lines }\end{array}$ & $\begin{array}{l}\text { No. of } \\
\text { exclusive } \\
\text { lines }\end{array}$ & $\begin{array}{c}\text { No. of } \\
\text { non- } \\
\text { exclusive } \\
\text { lines }\end{array}$ & $\begin{array}{l}\text { Strains with which } \\
\text { non-exclusive lines } \\
\text { are shared }\end{array}$ & $\begin{array}{c}\text { Strains with } \\
\text { which no } \\
\text { lines are } \\
\text { shared }\end{array}$ \\
\hline E 52 & I & 3 & 2 & $1 *$ & $\begin{array}{l}\text { E36, E } 16, \text { E } 1, \text { E } 56 \text { and } \\
\text { E55. E5 uncertain }\end{array}$ & E 58 \\
\hline E 55 & III & 1 & - & $1^{*}$ & $\begin{array}{l}\text { E } 1, \text { E } 56, \text { E } 16, \text { E } 52 \text { and } \\
\text { E36 }\end{array}$ & E 58 \\
\hline E5 & IV & 2 & 1 & $1^{*}$ & $\begin{array}{l}\text { E } 1, \text { E } 16 \text { and E } 56 . \text { E } 36, \\
\text { E } 52 \text { and E } 55 \text { uncertain }\end{array}$ & в 58 \\
\hline E16 & IV & 2 & 1 & $1^{*}$ & $\begin{array}{l}\text { E1, E 5, E 52, E 36, E } 56 \\
\text { and E55 }\end{array}$ & E 58 \\
\hline E 56 & IV & 1 & - & $1^{*}$ & $\begin{array}{l}\mathrm{E} 1, \mathrm{E} 5, \mathrm{E} 16, \mathrm{E} 36, \mathrm{E} 52 \\
\text { and E } 55\end{array}$ & E 58 \\
\hline E 1 & $\mathbf{V}$ & 2 & - & $\begin{array}{l}1^{*} \\
1\end{array}$ & $\begin{array}{l}\text { E5, E } 16, \text { E } 36, \text { E } 52, \text { E } 55 \\
\text { and E56 } \\
\text { E36 }\end{array}$ & E 58 \\
\hline E 36 & VI & 2 & - & $\begin{array}{l}1^{*} \\
1\end{array}$ & $\begin{array}{l}\text { E } 1, \text { E } 16, \text { E } 52, \text { E } 55 \text { and } \\
\text { E } 56 \\
\text { E } 1\end{array}$ & E 58 \\
\hline E 58 & VI & 3 & 3 & - & - & $\begin{array}{l}\text { All other } \\
\text { strains }\end{array}$ \\
\hline
\end{tabular}

\section{Immuno-electrophoresis}

In these experiments the TCA extracts of strains E 1, E5, E16, E36, E55 and E58 were used. The concentrated $H$ antisera were those prepared against strains E1, E8, E 5, E 52, E 55 and E 58 thought to be representative of different serological groups.

$T C A$ extract of $E 1$. Four lines, $a, b, c$ and $d$, were produced against the homologous antiserum. Two, $a$ and $b$, were located towards the positive electorde, $c$ close to the starting-point and $d$ towards the negative electrode. Line $a$, although continuous, produced two peaks, one at the starting-point and the other markedly towards the positive electrode, suggesting the presence of two electrophoretic components with the same immunological determinant groups. 
Against anti-E 8 serum lines identical to $a, b$ and $c$ were produced. Each of the antisera against E5, E 52 and E55 produced one line apparently corresponding to $a$.

Thus at least four antigens were revealed in $\mathrm{E} 1$ of which at least one is common to E5, E 52 and E55 and three to E 8 since it was shown up by their homologous antisera.

TCA extract of E5. Against the homologous antiserum two lines, $e$ and $f$, were produced which behaved similarly to $a$ and $c$ respectively of E 1 . Identical lines were formed with anti-E 1 serum. At least two antigens have, therefore, been shown to be common to $\mathrm{E} 1$ and $\mathrm{E} 5$.

Table 2. Summary of the results of Ouchterlony experiments with concentrated individual antisera to strains of Pseudomonas aeruginosa

Antisera for

E 1

E 5
E 8
E52
E55
E58

Antigens demonstrated

$$
\begin{aligned}
& \text { One* antigen common to E 5, E 16, E52, E55, E56 and E } 36 \\
& \text { One antigen common to E } 1 \text { and E 52 } \\
& \text { One antigen common to E 5 and E } 16 \\
& \text { Two* antigens in E } 36 \text { (one* apparently identical to those shared } \\
& \text { by all the strains except E 58) } \\
& \text { Two antigens in E } 1 \text { only } \\
& \text { Presumably all these must be present in E } 1 \\
& \text { One antigen in homologous strain only } \\
& \text { One antigen in each of E } 1 \text { and E } 36 \\
& \text { Two antigens in homolous strain only } \\
& \text { Two antigens in homologous strain only } \\
& \text { Two antigens in homologous strain: one exclusive and one } \\
& \text { shared with E } 36
\end{aligned}
$$

\begin{tabular}{|c|c|c|}
\hline Strain & $\begin{array}{c}\text { No. of } \\
\text { antigens } \\
\text { demonstrated }\end{array}$ & Antigens common to other strains \\
\hline E1 & 4 & $\begin{array}{l}\text { Two with E5 } \\
\text { One with each of E16, E } 36, \text { E } 52 \text { and E } 55\end{array}$ \\
\hline E5 & 3 & $\begin{array}{l}\text { Three with E } 16 \\
\text { Two with E } 1\end{array}$ \\
\hline E16 & 3 & $\begin{array}{l}\text { Three with E5 } \\
\text { One with each of E } 1 \text { and E52 }\end{array}$ \\
\hline E36 & 2 & $\begin{array}{l}\text { Two with E5 } \\
\text { One each with E } 1 \text { and E } 58\end{array}$ \\
\hline E 55 & 2 & One with E 1 \\
\hline E 58 & 3 & One with E36 \\
\hline
\end{tabular}

*Double lines were observed so two distinct antigens may be present.

Table 3. Summary of antigens in strains of Pseudomonas aeruginosa demonstrated by immuno-electrophoresis experiments

$T C A$ extract of $E 16$. With the anti-E 5 serum three lines, $g, h$ and $i$, were produced. Both $g$ and $i$ showed two peaks but the former was located towards the positive and the latter towards the negative electrodes. Line $h$ was situated towards the positive electrode. The antisera against $\mathrm{E} 1$ and $\mathrm{E} 52$ each produced one line; for the former similar to $g$ and for the latter to $h$.

This strain must contain at least three antigens, all of which are common to $\mathrm{E} 5$ 
since they were detected by using anti-E 5 serum. One of these is shared by $\mathrm{E} 1$ and another by $\mathbf{E} 52$.

$T C A$ extract of $E 36$. Both the antisera against $\mathrm{E} 5$ and $\mathrm{E} 8$ produced two lines, $j$ and $k$, in similar positions; the former towards the positive electrode and the latter at the starting point. The antisera against $\mathrm{E} 1$ and $\mathrm{E} 58$ each produced a line similar to $j$. The presence of two antigens, both common to $\mathrm{E} 5$, were, therefore, revealed. It also shares one antigen with each of $\mathrm{E} 1$ and $\mathrm{E} 58$.

$T C A$ extract of $E 55$. Two lines, $l$ and $m$, were produced against the homologous serum only. The former, which showed evidence of having two peaks, was located towards the positive electrode.

$T C A$ extract of $E 58$. Only the homologous antiserum reacted to produce a broad, diffuse line running from the origin to a point about $1.4 \mathrm{~cm}$. towards the negative electrode. At this point it split up into at least two lines, $n$ and $o$, both of which were convex towards the serum groove. A third line, $p$, distinct but broad with diffuse edges, was formed still further away on the cathode side.

The results of these experiments are summarized in Table 3.

\section{DISCUSSION}

Since Pseudomonas aeruginosa is liable to variation on repeated cultivation in the laboratory (Christie, 1948), serial subculture was avoided. Tests were restricted to those strains which survived drying and a fresh subculture from a dried pellet was used for every experiment. Other difficulties were:

(i) Variation in the number and nature of the antigens produced by one strain under different cultural conditions, sometimes but not always due to selection of mutants (see for example Pirt, Thackeray \& Harris-Smith, 1961). Although the conditions used by me were probably uniform, a complete investigation might call for the use of a variety of culture techniques.

(ii) The limits of concentration at which the antigen could be detected; the more concentrated the bacterial extract (and antiserum) used for the test, the more numerous the lines which appeared.

(iii) The choice of extractant for the antigens. Köhler (1957) preferred the Fuller formamide method to the Lancefield method because it extracted the minimum number of antigens needed to give clear-cut results in his investigation. Boivin \& Mesrobeanu's (1937) trichloroacetic acid method was used for the present work because of the experience already gained with it in this laboratory.

Agglutination and precipitin tests. In contrast to the results recorded by van den Ende (1952), the present precipitin tests with TCA extracts did not give such a clear picture. If these tests alone are taken as the basis for grouping, only 37 of 60 strains can be placed into groups. When these extracts were later submitted to the Ouchterlony technique, it appeared that their antigen contents were rather low. It is possible that precipitin tests with more concentrated extracts might have allowed more of the new strains to be grouped.

Although the percentage of strains which could be grouped was much lower than van den Ende's (1952), these results confirm his finding that at least six groups can be distinguished on the basis of precipitin tests with TCA extracts. The agglutination and precipitin tests with the 14 selected strains confirmed the existence of at least 
five groups, but it proved impossible to differentiate between strains E1, E6, E8 and $\mathrm{E} 42$.

Ouchterlony diffusion tests. Two of the more unfortunate phenomena found in Ouchterlony diffusion tests occurred with my Pseudomonas reagents: (a) the disappearance of lines of precipitate was occasionally observed; such lines gradually faded; $(b)$ the splitting of lines of precipitate was frequently observed. Initially single lines subsequently split to form double lines. Wilson \& Pringle $(1954,1955)$ observed the formation of multiple lines with advancing development and at very high relative concentrations of one of the reagents. Korngold \& van Leewen (quoted from Kabat \& Mayer, 1961, p. 89) attribute this effect to diffusion of excess antigen beyond the original line of specific precipitate to broaden the band or to form a second band. In my plates the strength and distance from the antigen well of many of the lines concerned is suggestive of a low antigen concentration rather than antigen excess. In these experiments mixtures of antigens were examined and it is not unlikely that two antigens having almost the same diffusion coefficient may, initially, form lines in the same position but that, given sufficient time, they may move further apart. Preference is therefore given to the interpretation that, in these experiments, double lines imply the presence of two antigens. In view of the possibility, however, that double lines may indicate the presence of one antigen only, the minimum numbers of antigens which were observed, and their distribution, in the eight strains tested are shown in Table 4.

Table 4. Distribution of twelve trichloroacetic acid-extractable antigens in eight strains of Pseudomonas aeruginosa

Grouping of strains, according to van den Ende, is based on the preliminary agglutination and precipitin tests.

$\begin{array}{lllllclll}\text { Strains ... } & \text { E1 } & \text { E5 } & \text { E16 } & \text { E36 } & \text { E52 } & \text { E55 } & \text { E58 } & \text { E56 } \\ \text { Groups ... } & \text { V } & \text { IV } & \text { IV } & \text { VI } & \text { I } & \text { III } & \text { VI } & \text { IV }\end{array}$

\begin{tabular}{|c|c|c|c|c|c|c|c|}
\hline & & & & & & & \\
\hline $\mathrm{A}^{*}$ & A & $\mathbf{A}$ & $\mathbf{A}$ & A & A & - & A \\
\hline B & B & B & $\bar{c}$ & - & - & - & - \\
\hline $\mathrm{C}^{*}$ & - & - & C & - & - & - & - \\
\hline D & - & - & - & D & - & - & - \\
\hline $\mathrm{E}$ & - & - & - & - & - & - & - \\
\hline$F$ & - & - & - & - & - & - & - \\
\hline 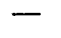 & $\mathbf{G}^{*}$ & - & $\bar{\pi}$ & - & - & $\overline{x x}$ & - \\
\hline- & - & - & $\mathbf{H}$ & - & - & $\mathbf{H}$ & - \\
\hline- & - & - & - & I & - & - & - \\
\hline- & - & - & - & - & J & $\overline{\mathrm{K}}$ & \\
\hline- & - & - & - & - & 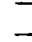 & $\hat{\mathrm{L}}$ & \\
\hline
\end{tabular}

*Double lines were observed so two distinct antigens may be present.

Strains E 1, E 5, E 16, E 36 and E 52 possess common antigens, as was suggested by the preliminary precipitin tests. It is also evident that $\mathrm{E} 1$ is very different from the others. Unfortunately $\mathrm{E} 8$ was lost during these experiments, but the results with anti-E 8 serum suggest a close similarity between $\mathrm{E} 1$ and $\mathrm{E} 8$. The results confirm the close relationship, if not identity, between E 5 and E 16 suggested by preliminary precipitin tests. Differences between E 56 and E 5 and E 16 and between E 36 and E58 are shown up.

Immuno-electrophoresis. These results confirmed those of the Ouchterlony experi- 
ments in showing that the strains investigated yielded many antigens of which several were common to more than one strain. For example, each of the strains, with the exception of E58, shared at least one antigen with $\mathrm{E} 1$.

\section{Conclusions}

Ouchterlony and immuno-electrophoresis experiments confirmed the multiplicity of antigens in Pseudomonas aeruginosa and the existence of five out of the six serological groups of van den Ende (1952).

Unless double lines in the Ouchterlony experiments indicate two antigens, 12 different TCA extracted antigens were demonstrated. Of these, seven were peculiar to certain strains, each thought to be representative of a different serological group, namely 2 to $\mathrm{E} 1,1$ to $\mathrm{E} 5,1$ each to $\mathrm{E} 52$ and $\mathrm{E} 55$ and 2 to $\mathrm{E} 58$. Immuno-electrophoresis also indicated the presence of at least one antigen peculiar to each of strains E1, E16, E55 and E58.

The cross-reactions which were observed in the preliminary precipitin tests are explicable in terms of the common antigens. An investigation of more strains out of each serological group may provide evidence that those antigens found to be peculiar to certain strains are the ones by virtue of which grouping is possible. These results extend those of van den Ende (1952) and emphasize the limitations of simple precipitin tests for demonstrating serological relationships.

This paper is based on a thesis submitted to the University of Cape Town, South Africa, in fulfilment of the requirements for the degree of Doctor of Philosophy. I record my sincere thanks to Professor A. Kipps, Professor in Bacteriology and Director of the Virus Research Unit, C.S.I.R. and University of Cape Town, and to Dr T. H. Mead, also of the Virus Research Unit, under whose supervision this work was done. Thanks are also due to Dr A. Polson, of the Virus Research Unit, for his personal interest, advice and helpful discussions. I am indebted to the academic and technical staff of the Department of Bacteriology and the Virus Research Unit for their assistance and to the South African Breweries Ltd. and to the South African Council for Scientific and Industrial Research for grants.

\section{REFERENCES}

AOKI, K. (1926). Agglutinatorische Einteillung von Pyocyaneusbazillen, welche bei verschiedenen Menschenerkrankungen nachgewiesen wurden. Zbl. Bakt. (Abt. 1, Orig.) 98, 186.

Boivin, A. \& Mesrobeanu, L. (1933). Contribution a l'étude de la composition chimique des bactéries. Substances azotées et phosphorées acid-solubles. C.r. Séanc. Soc. Biol. 112, 76.

Boivin, A. \& Mesrobeanu, L. (1937). Sur l'antigène 0; endotoxine des pyocyaniques. C.r. Séanc. Soc. Biol. 125, 273.

Cleve, von H. \& SCHwick, G. (1957). Immuno-elektrophoretische Serumanalyse bei Makroglobulinämie Waldenström. $Z$. Naturf. $12 \mathrm{~B}, 375$.

CHRISTIE, R. (1948). Observations on the biochemical and serological characteristics of Pseudomonas pyocyanea. Aust. J. exp. Biol. med. Sci. 26, 425.

Dulbecco, R. \& Vogt, M. (1954). Plaque formation and isolation of pure lines with poliomyelitis viruses. J. exp. Med. 99, 2.

GABY, W. L. (1946). A study of the dissociative behaviour of Pseudomonas aeruginosa. J. Bact. 51, 217.

Gould, J. C. \& McLeod, J. W. (1960). A study of the use of agglutinating sera and phage lysis in the classification of strains of Pseudomonas aeruginosa. J. Path. Bact. 79, 295.

Grabar, P. \& Williams, C. A. (1955). Méthode immuno-électrophorétique d'analyse de mélanges de substances antigéniques. Biochim. biophys. Acta 17.67. 
HIRSCHFELD, J. (1959). Immune-electrophoretic demonstration of qualitative differences in human sera and their relations to the haptoglobins. Acta path. microbiol. scand. 47, 160.

HIRSCHFELD, J. (1960). Immunoelectrophoresis. Procedure and application to the study of groupspecific variations in sera. Sci. Tools 7, 18.

Holloway, B. W. (1960). Grouping Pseudomonas aeruginosa by lysogenicity and pyocinogenicity. J. Path. Bact. 80, 448.

Homma, J. Y., Sagehashi, K. \& Hosoya, S. (1951). Serological types of Pseudomonas aeruginosa. Jap. J. exp. Med. 21, 375.

KABAT, E. A. \& MAYER, M. M. (1961). Experimental Immunochemistry, 2nd ed. Springfield, Illinois: Charles C. Thomas.

KöHLER, W. (1957). Zur Serologie der Pseudomonas aeruginosa. Z. Immun.Forsch. 114, 282.

LapresLe, C., KaminSKI, M. \& TANNER, C. E. (1959). Immunochemical study of the enzymatic degradation of human serum albumin: analysis of the antigenic structure of a protein molecule. J. Immunol. 82, 94.

MAYER, M. M., OSLER, A. G., BIER, O. \& HeIDELBERGER, M. (1946). The activating effect of magnesium and other cations on the haemolytic function of complement. J. exp. Med. 84, 535 .

MaYr-Harting, A. (1948). The serology of Pseudomonas aeruginosa. J. gen. Microbiol. 2, 31.

MeAD, T. H. \& VAN DEN ENDE, M. (1953). Bacteriophage inhibition by extracts from phage-insensitive bacteria of the genus Pseudomonas. J. Hyg., Camb. 51, 108.

Munoz, J., Scherago, M. \& Weaver, R. H. (1949). A serological study of members of the Pseudomonas genus. J. Bact. 57, 269.

OUCHTERLONY, Ö. (1949). Antigen-antibody reactions in gels. Acta path. microbiol. scand. 26, 507.

OUCHTERLONY, Ö. (1953). Antigen-antibody reactions in gels. IV. Types of reactions in coordinated systems of diffusion. Acta path. microbiol. scand. 32, 231.

Paigen, K. (1956). Convenient starch electrophoresis apparatus. Analyt. Chem. 28, 284.

PIRT, S. J., Thackeray, E. J. \& Harris-Smith, R. (1961). The influence of environment on antigen production by Pasteurella pestis studied by means of the continuous flow culture technique. J. gen. Microbiol. 25, 119.

SANDIFORD, B. R. (1937). Observations on Pseudomonas pyocyanea. J. Path. Bact. $44,567$.

SeleEn, W. A. \& Stark, C. N. (1943). Some characteristics of green-fluorescent pigment producing bacteria. J. Bact. 46, 491.

STAMP, LORD (1947). The preservation of bacteria by drying. J. gen. Microbiol. 1, 251.

VAN DEN ENDE, M. (1952). Observations on the antigenic structure of Pseudomonas aeruginosa. J. Hyg., Camb. 50, 405.

Verder, E. \& Watt, J. (1953). Studies of strains of Pseudomonas isolated from faecal specimens. Bact. Proc. p. 58.

WiLSON, M. W. \& Pringle, B. H. (1954). Experimental studies of the agar-plate precipitin test of Ouchterlony. J. Immunol. 73, 232.

WILSON, M. W. \& PRINGLE, B. H. (1955). Interpretation of the Ouchterlony precipitin test. J. Immunol. $75,460$. 